\title{
Seasonal influences on births and male sex skin coloration in rhesus monkeys (Macaca mulatta) in the southern hemisphere
}

\author{
C. Bielert and J. G. Vandenbergh* \\ Primate Behaviour Research Group and Department of Psychology, \\ University of the Witwatersrand, Johannesburg 2001, South Africa, and \\ * Department of Zoology, North Carolina State University, Raleigh, P.O. Box 5577, \\ North Carolina 27650, U.S.A.
}

\begin{abstract}
Summary. The annual distribution of births of rhesus monkeys in zoos in the southern hemisphere and changes in sex skin coloration in one colony were examined. Most (79\%) of the births occurred between October and January and the sex skin reached its greatest development during spring and early summer (i.e. at the time of mating). These results demonstrate a 6 -month reversal from the breeding activity of rhesus monkeys in the northern hemisphere.
\end{abstract}

\section{Introduction}

Seasonal breeding is well documented for a wide variety of primate species (Michael \& Zumpe, 1976; Van Horn, 1980). As for many vertebrates, photoperiod is an important influence on reproductive processes in several primates. Photoperiodic influences on gonadal function have been recorded for the mouse lemur, Microcebus murinus (Petter-Rousseaux, 1970, 1972), and the ring-tailed lemur, Lemur catta (Van Horn, 1975). However, less is known about the environmental factors regulating seasonal breeding in catarrhine monkeys and apes, although changes in vegetation as a result of seasonal rainfall have been suggested by Koford (1965) and Vandenbergh \& Vessey (1968) to be important in island colonies of rhesus monkeys (Macaca mulatta) near Puerto Rico. Vandenbergh (1973) reviewed data from several breeding populations of rhesus monkeys and suggested that decreasing daylength may induce changes necessary for the onset of the mating season but that other, more immediate, factors such as vegetation changes or social stimuli may be necessary for stimulating mating activities. Seasonal changes in circulating testosterone levels of male rhesus monkeys have been correlated with seasonal changes in sexual behaviour (Gordon, Rose \& Bernstein, 1976; Gordon, Bernstein \& Rose, 1978). In pigtail macaques (Macaca nemestrina), however, which breed throughout the year, no annual fluctuations in testosterone levels were observed (Bernstein, Gordon, Rose \& Peterson, 1978).

Considerable support for the idea of a photoperiod factor influencing the seasonal rhythm in the rhesus monkey comes from observations of animals living in the southern hemisphere. Hartman (1932) obtained information from curators of zoos in Australia and was able to document a birth season out of phase with that of the northern hemisphere by about 6 months. Since that time, reports have become available from Pretoria, South Africa (Brand, 1963), Sydney, Australia (Strahan, Newman \& Mitchell, 1971), and Rio de Janeiro, Brazil (Coimbra-Filho \& De A. Maia, 1977). 
In addition to birth records, changes in sex skin coloration of monkeys can also reveal changes in breeding activity. The male rhesus monkey has a sex skin which shows colour fluctuations sensitive to gonadal hormones (Vandenbergh, 1965) and to season and mating activities in free-ranging rhesus monkeys (Baulu, 1976).

The purpose of the present study was to examine the frequency of births and variations in seasonal sex skin coloration of rhesus monkeys living in colonies in the southern hemisphere.

\section{Materials and Methods}

To document the breeding activities of rhesus monkeys living in the southern hemisphere, questionnaires were sent in March 1975 to curators of all 10 of the zoological gardens listed in the International Zoological Garden Yearbook which were in the southern hemisphere. Replies were received from 8 of them and usable data were provided by 6 . Curators were asked to describe the caging arrangements of the animals and to provide birth information for animals that had been born within the past 5-7 years.

The statistical analysis of the birth data provided from the various zoos and from the colony at the South African Institute for Medical Research employed a Poisson distribution test since it was felt that the appropriate assumption requirements were met (Rao, 1952).

The data on sex skin coloration fluctuations were collected from the rhesus colony housed at the South African Institute for Medical Research's Rietfontein facility. The animals were housed in 12 cages, each of which measured approximately $2.5 \times 2.5 \times 4 \mathrm{~m}$. The wire cages all had a western exposure and included an indoor section for refuge during cold or wet weather. Six of the 9 males were housed with adult females and adolescents and 3 were housed together and with 2 adult females and a yearling female. The animals were fed daily a consistent ration of brown bread, carrots, cabbage, sweet potatoes and oranges; water was available ad libitum. Cages were hosed down daily and the animals were all in vocal communication with each other and were in visual communication with their nearest neighbours. Tactile contact with neighbours was prevented by a fine-mesh hardware cloth between cages. The animals were exposed to natural lighting and were at no time subjected to any artificial lighting or experimental manipulation.

Coloration ratings were made at close proximity on the 1 st and 15 th of each month for a 12-month period beginning on 1 July 1975. All ratings were made between 09:00 and 10:00 h local time. The face and the scrotum were individually rated employing a colour chart of 5 Munsell colours (see Table 1). It was thereoretically possible for a male to receive a total rating of 10 on any one occasion, but no such scores were ever achieved.

Table 1. Scoring values for the male sex skin coloration according to Munsell colours*

\begin{tabular}{lcccccc}
\hline Score value & 0 & 1 & 2 & 3 & 5 & 5 \\
Munsell colour & - & $5 R 8 / 4$ & $5 R 7 / 8$ & $5 R 6 / 10$ & $5 R 5 / 10$ & $5 R$ 4/14 \\
\hline
\end{tabular}

* Purchased from the Munsell Color Co., 2441 North Calvert Street, Baltimore, Maryland 212 18, U.S.A.

For statistical analysis of the sex skin coloration changes, a monthly average was determined for each male and the monthly data were then tested with a Friedman two-way analysis of variance (Siegel, 1956).

\section{Results}

The birth data are presented in Table 2. The 7 colonies from which data were taken recorded a total of 99 births. Data are also included from Pretoria and for comparison the combined data from 2 North American colonies are also presented. The birth data figures of the southern 
hemisphere colonies are displaced from those of the northern hemisphere by about 6 months and the births were not randomly scattered throughout the calendar year $\left(\chi^{2}=79.63\right.$, d.f. $=6, P<$ $0.001)$. The data presented also agree very well with those published for a Rio de Janeiro colony (Coimbra-Filho \& De A. Maia, 1977) in which births were recorded between October and March.

Table 2. The distribution of births by month in rhesus monkey colonies in the southern and northern hemispheres

\begin{tabular}{|c|c|c|c|c|c|c|c|c|c|c|c|c|c|c|}
\hline & & \multicolumn{12}{|c|}{ Month } & \multirow[b]{2}{*}{ Totals } \\
\hline & & $\mathbf{J}$ & $\mathrm{F}$ & $\mathbf{M}$ & A & $\mathbf{M}$ & $\mathbf{J}$ & $\mathrm{J}$ & A & S & 0 & $\mathbf{N}$ & D & \\
\hline \multicolumn{15}{|l|}{ Southern hemisphere } \\
\hline Pretoria, South Africa* & $25^{\circ} 45^{\prime} \mathrm{S}$ & 2 & 0 & 0 & 0 & 0 & 0 & 0 & 1 & 0 & 2 & 4 & 8 & 17 \\
\hline Johannesburg, South Africa & $26^{\circ} 10^{\prime} \mathrm{S}$ & 0 & 0 & 0 & 0 & 0 & 0 & 1 & 2 & 2 & 4 & 6 & 1 & 16 \\
\hline Perth, Australia & $31^{\circ} 58^{\prime} \mathrm{S}$ & 1 & 2 & 1 & 0 & 0 & 0 & 0 & 0 & 0 & 3 & 2 & 1 & 10 \\
\hline Sydney, Australia & $33^{\circ} 55^{\prime} \mathrm{S}$ & 1 & 0 & 0 & 1 & 0 & 0 & 0 & 1 & 0 & 1 & 2 & 1 & 7 \\
\hline Auckland, New Zealand & $34^{\circ} 56^{\prime} \mathrm{S}$ & 6 & 0 & 0 & 0 & 0 & 0 & 0 & 5 & 2 & 9 & 10 & 9 & 41 \\
\hline Adelaide, Australia & $36^{\circ} 55^{\prime} \mathrm{S}$ & 1 & 0 & 0 & 0 & 0 & 0 & 0 & 0 & 0 & 0 & 0 & 0 & 1 \\
\hline Melbourne, Australia & $37^{\circ} 45^{\prime} \mathrm{S}$ & 2 & 3 & 2 & 0 & 0 & 0 & 0 & 0 & 0 & 2 & 1 & 4 & 14 \\
\hline Wellington, New Zealand & $41^{\circ} 17^{\prime} \mathrm{S}$ & 2 & 0 & 1 & 0 & 0 & 0 & 0 & 0 & 0 & 3 & 3 & 1 & 10 \\
\hline Total & & 15 & 5 & 4 & 1 & 0 & 0 & 1 & 9 & 4 & 24 & 28 & 25 & 116 \\
\hline
\end{tabular}

Northern hemisphere

Atlanta, Georgia $\dagger$

$\begin{array}{llllllllllllll}33^{\circ} 45^{\prime} \mathrm{N} & 0 & 0 & 1 & 19 & 9 & 1 & 1 & 1 & 6 & 3 & 1 & 0 & 42\end{array}$

* Data from Brand (1963).

† Data from Vandenbergh (1973).

The median monthly sex skin coloration scores are presented graphically in Text-fig. 1 . The statistical analysis supported the view that months differed in their score values $\left(\chi^{2}=142\right.$, d.f. $=$ $11, P<0.001)$. The most intense sex skin coloration occurred from March to August, the period when fertile matings are expected after extrapolation from the birth season of the approximate gestation length of 168 days (Bielert et al., 1976).

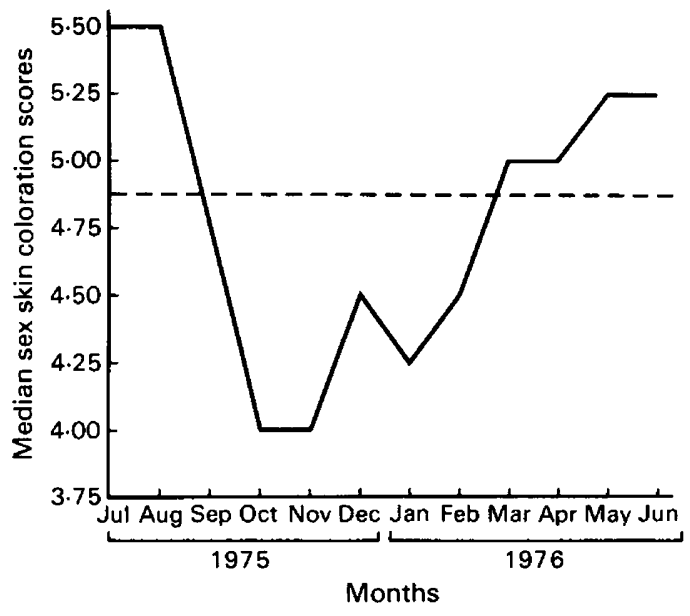

Text-fig. 1. Changes in the sex skin coloration (face and scrotum) of 9 adult male rhesus monkeys living in Johannesburg, South Africa, during a 12-month period. The colour scores were rated as indicated in Table 1 . The broken line indicates the median value for the whole study period. 


\section{Discussion}

The occurrence of births from October through January and the seasonal peak in sex skin colour in spring and early summer in rhesus monkeys residing in the southern hemisphere demonstrates a 6-month reversal from the seasonal breeding pattern seen in the northern hemisphere. The data presented for the pattern of breeding in the southern hemisphere agree closely with the findings of of Coimbra-Filho \& De A. Maia (1977) on a colony of rhesus monkeys near Rio De Janeiro, Brazil. In that colony, births were recorded between October and March. In the northern hemisphere, births typically occur in spring and early summer in wild or free-ranging populations of rhesus monkeys (Vandenbergh, 1973). Males also show a seasonal cycle which fluctuates in concert with the female reproductive activities. Sade (1964) found that free ranging rhesus monkeys on Cayo Santiago, an island near Puerto Rico, show a distinct seasonal cycle in testicular size and Conaway \& Sade (1965) showed that spermatogenesis ceased during the non-mating portion of the year. Testicular regression was accompanied by a loss in facial and scrotal sex skin coloration. In our study the male sex skin coloration scores were lowest during the season of births and highest during the season of conception.

The reproductive cycle shift and realignment to the photoperiod of the southern hemisphere is strong evidence that seasonal reproductive activity in the rhesus monkey may be tied to a daylength 'Zeitgeber'. The data collected do not allow us to exclude the possibility that other factors may be interacting with photoperiod to control the birth seasons of colonies at different latitudes. It may be that the involvement of daylength is relatively passive through the induction or maintenance of a physiological state in which the animals are primed to respond to more immediate stimuli, because social and other transient ecological factors, such as variations in vegetation, also seem to play a role in the timing of mating (Vandenbergh, 1973, 1977).

We thank the curators who replied to the questionnaires; the South African Institute for Medical Research, and in particular Mr Hodgson, for facilities and help with the animals; the University Council of the University of the Witwatersrand for financial support; Mrs B. Hurwitz for typing the manuscript; and Dr C. Anderson for her critical reading of the manuscript.

\section{References}

Baulu, J. (1976) Seasonal sex skin colouration and hormonal fluctuations in free-ranging and captive monkeys. Horm. \& Behav. 7, 481-494.

Bernstein, I.S., Gordon, T.P., Rose, R.M. \& Peterson, M.S. (1978) Influences of sexual and social stimuli upon circulating levels of testosterone in male pigtail macaques. Behav. Biol. 24, 400-404.

Bielert, C., Czaja, J.A., Eisele, S., Scheffler, G., Robinson, J.A. \& Goy, R.W. (1976) Mating in the rhesus monkey (Macaca mulatta) after conception and its relationship to oestradiol and progesterone levels throughout pregnancy. J. Reprod. Fert. 46, 179-187.

Brand, D.J.L. (1963) Records of mammals bred in the National Zoological Gardens of South Africa during the period 1908-1960. Proc. zool. Soc. Lond. 140, $617-659$.

Coimbra-Filho, A.F. \& De A. Maia, A. (1977) As fases do processo reproductivo de Macaca mulatta Zimmermann, 1780, na Ilha Do Pinheiro, Rio de Janeiro, Brasil (Cercopithecidae, Primates). Rev. Brasil Biol. 37, 71-78.

Conaway, C.H. \& Sade, D.S. (1965) The seasonal spermatogenic cycle in free-ranging thesus monkeys. Folia primat. 3, 1-12.
Gordon, T.P., Rose, R.M. \& Bernstein, I.S. (1976) Seasonal rhythms in plasma testosterone levels in the rhesus monkey (Macaca mulatta): a three-year study. Horm. \& Behav. 7, 229-243.

Gordon, T.P., Bernstein, I.S. \& Rose, R.M. (1978) Social and seasonal influences in the male rhesus monkey. Physiol. Behav. 21, 623-627.

Hartman, C.G. (1932) Studies in the reproduction of the monkey Macacus (Pithecus) rhesus, with special reference to menstruation and pregnancy. Contrib. Embryol. Carneg. Instn 134, 3-160.

Koford, C.B. (1965) Population dynamics of rhesus monkeys on Cayo Santiago. In Primate Behavior: Field Studies of Monkeys and Apes, pp. 160-174. Ed. I. DeVore. Holt, Rinehart and Winston, New York.

Michael, R.P. \& Zumpe, D. (1976) Environmental and endocrine factors influencing annual changes in sexual potency in primates. Psychoneuroendocrinology 1, 303-313.

Petter-Rousseaux, A. (1970) Observations sur l'influence de la photo période sur l'activité sexuelle chez Microcebus murinus (Miller, 1777) en captivité. Annls Biol. anim. Biochim. Biophys. 10, 203-208. 
Petter-Rousseaux, A. (1972) Application d'un système semestrial de variation de la photo période chez Microcebus murinus (Miller, 1777). Annls Biol. anim. Biochim. Biophys. 12, 367-375.

Rao, C.R. (1952) Advanced Statistical Methods in Biometric Research. John Wiley, New York.

Sade, D.S. (1964) Seasonal cycle in size of testes of free-ranging Macaca mulatta. Folia primat. 2, $171-180$.

Siegel, S. (1956) Nonparametric Statistics for the Behavioral Sciences. McGraw-Hill, New York.

Strahan, R., Newman, P.J. \& Mitchell, R.J. (1971) Times of birth of thirty mammal species, bred in the zoos of London and Sydney. Bull. Zoo Manage. 3, 384-386.

Vandenbergh, J.G. (1965) Hormonal basis of sex skin in male rhesus monkeys. Gen. comp. Endocr. 5, 31-34.

Vandenbergh, J.G. (1973) Environmental influences on breeding in rhesus monkeys. In Symp. 4th Int. Congr. Primat. Vol. 2: Primate Reproductive Behavior, pp. 1-19.

Vandenbergh, J.G. (1977) Social influences on reproduction in rhesus monkeys. In Use of Nonhuman Primates in Biomedical Research, pp. 174-182. Eds M. R. N. Prasad \& T. C. Anand Kumar. Indian National Science Academy, New Delhi.

Vandenbergh, J.G. \& Vessey, S. (1968) Seasonal breeding of free-ranging rhesus monkeys and related ecological factors. J. Reprod. Fert. 15, 71-79.

Van Horn, R.N. (1975) Primate breeding season: photo periodic regulation in captive Lemur catta. Folia primat. 24, 203-220.

Van Horn, R.N. (1980) Seasonal reproductive patterns in primates. Prog. reprod. Biol. 5, 181-221.

Received 24 October 1980 